\title{
Affect, perceptual experience, and disclosure
}

\author{
Daniel Vanello ${ }^{1}$
}

Published online: 21 July 2017

(c) The Author(s) 2017. This article is an open access publication

\begin{abstract}
A prominent number of contemporary theories of emotional experienceunderstood as occurrent, phenomenally conscious episodes of emotions with an affective character that are evaluatively directed towards particular objects or states of affairs - are motivated by the claim that phenomenally conscious affective experience, when appropriate, grants us epistemic access not merely to features of the experience but also to features of the object of experience, namely its value. I call this the claim of affect as a disclosure of value. The aim of this paper is to clarify the sort of assumptions about experience that we ought to avoid if we want to be able to argue that for the claim of affect as a disclosure of value. There are two core arguments in this paper. First, I argue that Mark Johnston's account of affect as a disclosure of value, due to its naïve realist commitments, relapses into a position that is vulnerable to the same objection put forward by some naïve realists against intentionalist accounts of perceptual experience. Second, I argue that Michelle Montague's account, due to its phenomenal intentionalist commitments, relapses into a position that is vulnerable to the same objections put forward against qualia theories of the phenomenal character of perceptual experience. The upshot of the paper is that the core assumptions embedded in the three dominant models of experience - namely naïve realism, different versions of intentionalism, and qualia theory-are problematic as found in contemporary accounts of affect as a disclosure of value.
\end{abstract}

Keywords Affect $\cdot$ Perceptual experience $\cdot$ Disclosure $\cdot$ Value

Daniel Vanello

tativanello@gmail.com

1 Department of Philosophy, Social Sciences Building, University of Warwick, Coventry

CV4 7AL, UK 


\section{Introduction}

In her papers "The Logic, Intentionality, and Phenomenology of Emotion" (2009) and "Evaluative Phenomenology" (2014), Michelle Montague defends the view that the affective and evaluative components of emotional experience are inextricably intertwined (see also Montague 2016, ch. 9). ${ }^{1}$ Towards the end of her "Evaluative Phenomenology," there is a passage that expresses Montague's underlying thought about the phenomenon she seeks to capture through a defence of her inextricability claim:

So, although one may be able to know intellectually (in some sense) that the death of a friend is of disvalue, and indeed that such a death is sad without feeling an emotion, one can experience the disvalue of the friend's death in this distinctive way only if one has an emotional experience. Data in Star Trek, who does not have any emotions, may be capable of saying what is of value and disvalue, and in turn saying what is sad and what is happy, but he cannot experience sadness or happiness and thus he cannot experience value or disvalue (in the special way I am indicating). A stronger claim about Data, which I do not have the space to pursue in this chapter, is that although he can say what is of value and disvalue, and know what is of value and disvalue, he cannot really know value and disvalue. It may be similar to someone who is blind from birth who can say this is red, when told that it is a ripe tomato, and indeed know that it is red, but not know what red is. (Montague 2014, 47)

Montague distinguishes between two claims. First, unless one is able to experience emotions, one cannot experience value. I believe that the way we should interpret this claim is as entailing the belief that phenomenally conscious affective experience, when appropriate, is the disclosure not merely of properties of experience but also of properties of the object of experience, namely its value. The interpretation gains plausibility when we look at the second, stronger claim that the first one is meant to be a prelude to. The second claim is that phenomenally conscious affective experience provides us with a distinctive sort of knowledge about value that cannot be acquired in the absence of affect. Montague seems to suggest, correctly, that the second claim cannot be secured without securing the first claim. That is, the claim that affect provides us with a distinctive sort of evaluative knowledge cannot be secured without securing the claim that the presence of affect discloses not only features of experience but also of the object of experience. That is because in disclosing features of the object of experience rather than merely of the

\footnotetext{
1 The experiential dimension of an emotion refers to that aspect of an emotion that is occurrent, episodic and has phenomenal character. In this paper I assume that indeed emotional experience involves an evaluation. More precisely, I focus on emotional experience as involving an evaluation of particular objects. By this I do not mean to include solely particulars occupying a spatio-temporal position in the actual world and which are present but also objects and states of affairs that are imagined, objects and states of affairs that belong to the past and future, conceivable states of affairs and objects, and so on. By "affect" philosophers generally refer to that feeling-component of an emotional experience that we often express as "moving" or "touching" us. For a review of the literature that accepts this characterisation of emotional experience, see Deonna and Teroni (2012).
} 
experience itself, affect grants us epistemic access to the very features of the object of experience, namely its value, and can therefore potentially ground the distinctive sort of evaluative knowledge Montague is hinting at. In the remainder of this paper, I will refer to the claim that phenomenally conscious affective experience provides us with epistemic access to features of the object of experience, namely its value, as the claim of affect as a disclosure of value.

According to Montague, her argument to the effect that the affective and evaluative components of emotional experience are inextricably linked is meant to secure the first claim, namely affect as a disclosure of value, not the second. In order to secure the second claim, one would need to show not only that affect grants us epistemic access to the evaluative features of the object of experience, but also specify what sort of knowledge is at stake and the sort of justification that characterises it. Although Montague is clear that her arguments are not meant to secure the second claim, it is not farfetched to suggest that it is the second claim that truly motivates Montague's argument to the effect that the affective and evaluative components of emotional experience are inextricably intertwined. Indeed, the same intuition found in Montague's second claim is found in several contemporary philosophical accounts of the emotions. For instance, in his "The Authority of Affect", Mark Johnston argues that

Just as we need to sense cherry red to make a goodish range of judgments as to its nature, we need to encounter the determinate sensuous values in order to have them either as the topics or as the things predicated in our most basic evaluative judgements... If one has never been moved or affected by the determinate ways in which things are beautiful or charming or banal or sublime or horrific or appealing, then one is ignorant of the relevant determinate values. (Johnston 2001, 182-183)

Just like Montague, Johnston argues that reason and the understanding alone cannot provide us with insight into values (ibid., 182). ${ }^{2}$ There must be an affective engagement with the object in order to access its value. Crucially, underlying the accounts of affect as a disclosure of value of both Montague and Johnston is an analogy with perceptual experience. Since we gain epistemic access to, or disclosure of, sensory properties such as colour solely in virtue of having a veridical phenomenally conscious sensory experience, then phenomenally conscious sensory experience plays an essential role in the acquisition of knowledge of our surroundings. Analogously, since we gain epistemic access to, or disclosure of, the evaluative features of objects solely in virtue of having an appropriate phenomenally conscious affective experience, then phenomenally conscious affective experience plays an essential role in the acquisition of evaluative knowledge. This is not to say that therefore either Montague or Johnston should be read as arguing that emotional experience is a sort of perceptual experience of

\footnotetext{
${ }^{2}$ For other accounts motivated by the intuition that the affective component of emotional experience provides us with a distinctive sort of epistemic access to the value of the object of experience, see e.g., Goldie (2000, 2002), Helm (2001), Zagzebski (2003), Doering (2007), Deonna and Teroni (2014, 2015), Poellner (2016).
} 
value. ${ }^{3}$ Rather, these authors rely on theories of perceptual experience in order to argue for the claim that affective experience discloses not merely features of experience but also of objects of experience, namely their value.

The aim of this paper is to argue that Montague's and Johnston's accounts are unable to secure the claim that affective experience discloses features of the object of experience, namely its value, rather than merely features of the experience itself. I argue that they are unable to do so due to the assumptions about experience that they inherit from their underlying theories of perceptual experience. The upshot is that the sort of assumptions about experience embedded in the most prominent contemporary theories of perceptual experience—contemporary versions of qualia theories, different versions of intentionalism, and naïve realism- are potential obstacles to defending the claim of affect as a disclosure of value. Moreover, what emerges from my critical assessment of Montague's and Johnston's accounts is the implausibility of attempting to capture the claim of affect as a disclosure of value by relying only on tools provided by theories of experience. That is, the critical assessment highlights the lack in the above attempts to account for the sort of property that emotional experience is meant to be disclosing i.e. value. Although it is not in the scope of this paper to provide an account of what sort of property value is such that it can be disclosed by affective experience, I believe that the critical assessment of Montague's and Johnston's theories found in this paper will render salient the implausibility of attempting to capture the claim of affect as a disclosure of value without attempting to give an account of what sort of property value is. The overall conclusion of this paper, then, is that if we want to capture the claim that affect is the disclosure of value, we cannot rely solely on assumptions made by contemporary theories of experience.

My strategy is the following. In Sect. 2 I clarify the assumptions embedded in the intentionalist model of experience and its "qualia option". I then present the objection against intentionalists put forward by some naïve realists in the literature on sensory experience. The objection consists in the claim that appeal to experience having "representational content" is unable to show that the phenomenal character of experience grants us epistemic access to the features of the object of experience. In Sect. 3 I clarify Johnston's naïve realist commitments in his account of affect as a disclosure of value. This allows me, in Sect. 4, to argue that Johnston's commitment to a naïve realist conception of experience, when applied to affect and value, leads him to adopt a position that is vulnerable to the same charge that some naïve realists put forward against a variety of intentionalist accounts of perceptual experience. In Sect. 5 I move to Montague's account of emotional experience. Recent attempts in the literature on perceptual experience to reply to the objection put forward by naïve realists rely on arguments deriving from the "phenomenal intentionalist" camp, a relatively recent variety of intentionalism. ${ }^{4}$ Phenomenal intentionalists promise to

\footnotetext{
3 For a defence of the perceptual model of emotional experience, see Zagzebski (2003), Doering (2003, 2007), Goldie (2007), Tappolet (2012), Poellner (2016), Cowan (2016). For arguments against it, see Whiting (2012), Deonna and Teroni (2012, ch. 6), Brady (2013).

4 For the "phenomenal intentionality research project", see Kriegel (2013). For a more specific elaboration of the view, see Farkas (2013). For early versions of phenomenal intentionalism, see Horgan
} 
be able to show that the phenomenal and the intentional are inextricably linked without falling back into a form of qualia theory or more traditional forms of intentionalism. In so doing, they argue they can show that phenomenally conscious experience grants us epistemic access to the features of the object of experience. In this section I show how Montague's account of emotional experience is an instance of applying assumptions about experience deriving from the phenomenal intentionalist camp onto emotional experience. I then argue, in Sect. 6, that Montague's account, and in particular her arguments, fail to secure the inextricability of phenomenology and intentionality in emotional experience and therefore her position is vulnerable to the same problems that besiege qualia theories of experience, namely ones that do not allow us to show that the phenomenal character of experience discloses features of the object of experience rather than only of experience. I conclude that therefore it is not clear that a phenomenal intentionalist reply to the argument put forward by naïve realists against the intentionalist model is a viable option in theories of affective experience and value. In the concluding section, I suggest what sort of accounts of evaluative properties are best suited to capture the notion of affect as a disclosure of value.

\section{Intentionalism, qualia, and the naïve realist objection}

According to an intentionalist model, perceptual experience is a kind of mental representation. The intentionalist model makes use of the notion that perceptual experience has intentional, or representational, content in order to cash out the thought that the object of perceptual experience, say a chair, is represented as being a certain way to the subject of experience, say as brown. According to the intentionalist, the representational content of perceptual experience has veridicality conditions. In case the perceptual experience is veridical, the properties represented by the content of the experience are the properties of the object of experience out there in the world. In case the experience is illusory or hallucinatory, the properties represented by the content of experience are not the properties of the object out there in the world. Nevertheless, the perceptual experience is still intentional insofar as it still has content, albeit one that misrepresents the world. According to the intentionalist, then, both veridical and illusory or hallucinatory experiences have something in common, namely representational content. This is how the intentionalist model explains the phenomenological indistinguishability between a veridical and illusory or hallucinatory experience. Importantly, intentionalists argue that in employing the notion of representational content there is no commitment to the claim that perceptual experience entails a veil of appearance or intermediary mental object between the subject and the object. There is also a second feature of the structure of perceptual experience that intentionalists take to determine its

Footnote 4 continued

and Tienson (2002) and Loar (2003). The notion of qualia has itself been widely debated. For a useful account of the history of the term, see Crane (2000). 
representational character: this is the intentional attitude that is taken towards the representational content.

There seem to be two broad ways in which the intentionalist model understands the relation between the phenomenal character of experience and its intentionality. The first way is by drawing an intimate connection between the phenomenal character and the experience's representational properties. According to this sort of intentionalist, the phenomenal character of a perceptual experience is determined by the representational properties of the experience. The representational properties of the experience are the properties the experience has due to its representational content and the intentional attitude taken towards it. Although different forms of this sort of intentionalist theory disagree on whether the phenomenal character is determined wholly by the representational content or whether the intentional attitude also has a role to play, they agree that ultimately the phenomenology of perceptual experience is determined by the representational properties of the experience. $^{5}$

The second way that the intentionalist can account for the phenomenal character of experience is by arguing that rather than being determined by the representational features of experience, the phenomenal character is determined by qualia, that is, non-intentional, or non-representational, intrinsic properties of experience. In this case, what it is like to visually experience, say, a brown chair is determined by an intrinsic, non-intentional feature of experience associated with "brown-ness." Notice that in both intentionalist options it is a property of experience that determines its phenomenal character: in the first case the representational properties of experience and in the second the intrinsic properties of experience, namely qualia. Crucially, though, while the first way of explaining the phenomenal character of experience is committed to the inextricability between phenomenology and intentionality, the second is not. This is so because while in the first case it is the representational properties of the experience that determines the properties of its phenomenal character, in the second case the phenomenal character is determined by qualia which potentially have no necessary relation with the intentional structure of the experience. In other words, while in the first case it follows that if we alter the representational properties of the experience then necessarily we alter its phenomenal character, and vice versa, in the second case it is at the very least conceivable that we can alter the phenomenal character (qualia) of the experience without altering its representational properties. Opting for the latter strategy is therefore problematic for an account that wants to argue that phenomenally conscious experience plays an essential role in granting us epistemic access to the features of the object of experience rather than merely of the experience itself. For if phenomenal character is determined by properties of experience that are not necessarily related to the experience's representational properties, why should we think that it plays an essential role in granting us epistemic access to the features of

\footnotetext{
${ }^{5}$ For the view that the phenomenal character of experience is determined solely by the representational content, see Tye (1992); while for the view that the intentional attitude has also a determining role to play in the phenomenal character, see Crane (2009).
} 
the object of experience. I will therefore assume from now on that the qualia option is inherently problematic for an account of affect as a disclosure of value.

Is the intentionalist model of experience able to show that its phenomenal character plays an essential role in the acquisition of knowledge of one's surroundings? According to some naive realists, it is not. ${ }^{6}$ The reason is that, according to some naïve realists, it is unclear why the possession of a representational content should suffice to make a mental state phenomenally conscious. If, then, our access to properties of the object is by means of representational content, then the phenomenal character of experience does not play a necessary role in the epistemic access to the properties in question. Let me illustrate with the case of Jackson's Mary. When Mary is confronted for the first time with a red object, she acquires a new phenomenal conception of redness due to her experience representing the colour red in a new, phenomenal way. In both the case of representing redness by its physical constituents -as Mary is able to do before leaving the black and white room- and representing redness in the new, phenomenal way, redness is precisely represented by the experience to Mary. But why should we think that the representational content of this new, phenomenal way of representing redness, even if veridical, qualifies as a genuine case of disclosure of the properties of the object of experience when the representational content of the other, non-phenomenal ways of representing redness that Mary possessed before leaving the room do not qualify as genuine cases of disclosure? And therefore why should we think that the phenomenal character of this new way of representing redness is playing an essential role in Mary's epistemic access to redness itself? If the phenomenal character of Mary's sensory experience of red is determined by the experience's representational content, then the phenomenal character of her experience teaches her a new way of representing redness, not what redness is like. If so, then it is unclear how the phenomenal character of Mary's experience is playing an essential role in her acquisition of knowledge regarding what redness is.

\section{Naïve realism and the "as-structure" of experience}

How does Johnston's naïve realism differ from the intentionalist? The broader answer lies in Johnston's rejection of the conception of sensory experience as providing us with a mental representation of the world. Rather, according to Johnston, (veridical) sensory experience is to be conceived as a psychological, nonrepresentational relation between the subject and the particular worldly objects out there in the world. The crux of Johnston's theory is that veridical sensory experience provides us with worldly particulars instantiating what he terms "sensible profiles", that is, 'a complex, partly qualitative and partly relational property, which exhausts the way the particular scene before your eyes is if your present experience is veridical' (Johnston 2004, 134). According to Johnston, we

\footnotetext{
${ }^{6}$ For a version of the following argument, see Campbell's contribution in Campbell and Cassam (2014); see also Soteriou (2016, 93-111).
} 
should think of sensible profiles as pertaining to the world insofar as they just are the sensible way that an arrangement of particular worldly objects and their properties strikes us as being. In other words, sensible profiles are properties of the scenes we are confronted with, scenes constituted by a particular arrangement of worldly objects and their properties. Johnston invites us to think of sensible profiles through Wittgenstein's notion of "seeing as" (Johnston 2004, 137). In having a veridical perceptual experience of a pine tree, the object of my experience is the particular pine tree before me that instantiates the sensible profile "as a pine tree". The sensible profile just is the arrangement of the tree's properties that allows me to see it as a pine tree. The characterization of sensible profiles in terms of "seeing as" is important because it allows Johnston to explain how our sensing can be expanded beyond the sensing of standard properties such as colour and shape and therefore to talk of sensing 'considered generally'. This is so because our ability to see things "as" is expanded by our conceptual abilities. I am able to see my dog as a Golden Retriever because I possess the concept "Golden Retriever."

What about cases of hallucination or perceptual illusion? In cases of hallucination or perceptual illusion, Johnston argues that we are still presented with sensible profiles, the "only" difference being that these are not instantiated by particular objects in the world. According to Johnston, if I hallucinate a pine tree, or fall under the illusion that the tree before me is a pine tree, I am nevertheless presented with a sensible profile- not instantiated in the world. Crucially, this does not mean that I am presented with a mental item. Sensible profiles are not properties of experience. They are complex properties instantiated by particular objects in the world that can be detected by sensory awareness in case of veridical perceptual experience and that are not instantiated by objects in case of hallucinations or perceptual illusions. In both the case of hallucinatory, or illusory experience, and veridical experience, the phenomenal character of experience is to be understood (in part) in terms of the subject's awareness of an item that is not a property of the experience.

Importantly, according to Johnston, although the phenomenological indistinguishability between a veridical perceptual experience and a hallucination is accounted for by the characterization of both sorts of experiences as an awareness of sensible profiles, it does not follow that then these two sorts of experiences are directed towards the same kind of object. In the case of veridical perceptual experience, we are presented with particular worldly objects that instantiate sensible profiles while in hallucination we are presented with sensible profiles that are not instantiated. To assume that in both cases we are presented with the same kind of object, namely sensible profiles, is to assume what Johnston calls the 'The Phenomenal Bottleneck Principle' according to which '[i]f two acts of awareness are qualitatively indistinguishable for their subject then objects of the very same type are directly presented in each act of awareness' (Johnston 2004, 151). For our purposes, what is important to highlight is that by rejecting 'The Phenomenal Bottleneck Principle', Johnston rejects the assumption that we gain access to particular worldly objects by being presented with sensible profiles. Rather, Johnston's thought is that we are presented with particular objects as having sensible profiles. As Johnston puts it, 'the 'as'-structure of sensory awareness is not 
the loaded 'by'-structure of the friend of indirection' (ibid, 155). This is important because, as we shall see presently, it reveals what Johnston takes to be a defining feature of experience that distinguishes him from the representationalist.

In opposition to the intentionalist, then, Johnston rejects the idea that in both veridical perceptual experience and hallucination we are presented with the same sort of object where this is conceived as a property of experience. ${ }^{7}$ Rather, what the two experiences share is being an awareness of a complex property i.e. a sensible profile, where this property is not a property of the experience but rather, in the case of a veridical perceptual experience, it is a property instantiated by the particular objects out there in the world. So in the case of veridical perceptual experience, the phenomenal character is constituted (in part) by the very features of the objects we are confronted with. And in the case of hallucinatory experience, the phenomenal character is constituted by non-instantiated sensible profiles. Crucially, then, contra the intentionalist, Johnston maintains that in the case of veridical perceptual experience, the phenomenal character of sensory experience is not ultimately constituted solely by properties of the experience, properties that it shares with hallucinatory experience. Rather, the phenomenal character is (in part) constituted by the qualitative features of the particular worldly objects confronting the subject.

We are now in the position to appreciate what is at stake in Johnston's account of affect as a disclosure of value. Johnston claims that his 'thought about the sensuous values is that exemplifications of them can typically be sensed only when sensing is refined by affect' (Johnston 2001, 210). First, recall that the objects of veridical sensory awareness are the particular objects we are confronted with that instantiate sensible profiles, where the notion of sensible profiles is comparable to Wittgenstein's "seeing as". So when Johnston speaks of affect as a refinement of sensing he means that in an affective experience, just like in a sensory experience, particular worldly objects strike us as being a certain way, in this case as exemplifying certain values. Most importantly, what the above discussion of the difference between Johnston and the representationalist brings out is that the way we are to think of the phenomenal character of a veridical affective experience, according to Johnston, is as constituted by the way that the particular worldly objects are, that is, as instantiating evaluative properties. According to Johnston, this naïve realist claim is captured by the notion of "seeing-as": affect is the presentation of particular objects in the world as exemplifying the sensible profile of an evaluative property. It is in this way that we should understand Johnston's claim that affect is the disclosure of value.

\section{Affect and the as-structure of experience}

Does Johnston's account of affect as a disclosure of value deliver on its promise? When we ask the same question for the case of visually experiencing a red object, and if we accept Johnston's conception of the phenomenal character of experience,

\footnotetext{
7 Here I do not in any way mean to suggest that representationalists deny that in experience we are presented directly with the mind-independent object and its features.
} 
the answer is: yes, Johnston's account does have the resources to show that phenomenally conscious sensory experience grants us epistemic access to the features of the object of experience and that therefore it plays an essential role in the acquisition of knowledge of what the relevant property is. That is because the phenomenal character of seeing, say, red just is (in part) being presented with redness itself. According to this conception of the phenomenal character of experience, we cannot learn what redness itself is unless we have a visual experience with that phenomenal character. Can we hold on to a similar thought once we shift to affect and value?

The answer is, no. Let me begin by noting that in order to explain the role played by the phenomenal character of the visual experience of a red object in acquiring knowledge of what redness is like, there is no immediate need to introduce the "asstructure" of sensory experience that Johnston takes it to have. More specifically, there is no immediate need to cash out the thought that a phenomenally conscious visual experience presents us with the colour red itself by saying that visual experience presents the object as red. We simply point out that redness itself (in part) constitutes the phenomenal character of the experience. Yet, once we turn to properties whose manifestation in experience is explained by Johnston in terms of sensible profiles, the need to introduce the "as-structure" of experience to cash out the naive realist claim that the phenomenal character of a veridical sensory experience presents us with the property itself, insofar as it is (in part) constituted by the relevant property, becomes more pressing. These cases include both evaluative properties and the sort of properties that Johnston argues can be sensed by conceptually refined, non-affective episodes of sensory awareness, such as a tell in poker or a double fork in chess.

To illustrate, consider the sort of properties Johnston argues can be rendered manifest by conceptually refined, non-affective sensory experiences, such as a double fork in chess. Once Johnston wants to show that a double fork tactic is itself present in the phenomenal character of sensory experience, and thus that the latter plays an essential role in acquiring knowledge of what the former is, Johnston employs the notion that the double fork's sensible profile constitutes (in part) the phenomenal character of the sensory experience. As Johnston points out, the conceptual refinement needed to detect a double fork in chess is what allows us to direct our attention to the relevant features of the situation thus charting the territory of its sensible profile (ibid.,). For instance, the conceptual refinement of our sensibility directs our attention to the position of the knight in relation to both the pawn and the rook. In so doing, the sensible profile of the double fork is rendered manifest to us and therefore, according to Johnston, it constitutes (in part) the phenomenal character of sensory experience. The essential role of the phenomenal character in rendering manifest a double fork is captured in terms of the phenomenal character playing an essential role in experiencing the position of the knight in relation to the pawn and rook as a double fork tactic. Here, the "as-structure" of experience is appealed to in order to render intelligible the manner in which the double fork is rendered manifest in the phenomenal character of experience.

Turning to evaluative properties, take Johnston's example of sensing the ravishingness of Yo Yo Ma's tone in his cello playing. Once Johnston wants to 
claim that the tone's ravishingness is itself present in the phenomenal character of affective experience, and thus that the latter plays an essential role in acquiring knowledge of what the former is, Johnston employs the notion that the sensible profile of the tone's ravishingness constitutes (in part) the phenomenal character of the affective experience. Analogously to the case of the double fork, the conceptual refinement of the affective experience directs our attention to the features constituting the sensible profile of the tone's ravishingness until it is rendered manifest to us. Again, the essential role of the phenomenal character in rendering manifest the ravishningness of the tone is captured in terms of the phenomenal character playing an essential role in experiencing the various features of the tone as ravishing. Notice that the same works for cases where the sensuous value is detected by an affective experience that is not conceptually refined, such as feeling repulsed at decaying organic matter (ibid., 184): the manner in which the feeling of disgust presents us with the repulsiveness itself of decaying organic matter is cashed out in terms of the affective character of the experience presenting the decaying organic matter as repulsive.

Notice that I am not suggesting that, according to Johnston, in the case of affect and conceptually refined forms of non-affective sensory awareness, the relevant properties are somewhat "hidden" from view and that the subject, in sensing the relevant sensible profile, conjectures their presence. Johnston is explicit in denying this (ibid., 200). According to Johnston, sensuous values and properties such as a double fork in chess are there in the scene to be detected by an appropriately refined sensibility in the same way that the colour red is there to be detected by sensory awareness. Rather, what I am suggesting is that Johnston is forced to call into play the notion of the "as-structure" of experience once he seeks to put on a par the intelligibility of the presence in the phenomenal character of experience of properties such as the colour red and unconventional cases of property disclosure such as a double fork in chess and sensuous values such as the ravishingness of a tone and the repulsiveness of decaying organic matter.

I now want to argue that appealing to the "as-structure" of sensory awareness impedes Johnston in capturing the claim that the phenomenal character of experience plays an essential role in granting us epistemic access to the features of the object of experience rather than merely of the experience itself. Consider the following. So far, we have agreed that in the case of redness, what Mary is ignorant of before seeing for the first time a red object is what redness is. Johnston's naïve realism is in principle capable of capturing the claim that once Mary exits her black and white room and enjoys a phenomenally conscious visual experience of a red object, the phenomenal character of her experience plays an essential role in granting her access to what redness is and this is because the phenomenal character of her visual experience is (in part) constituted by redness itself. Now consider an analogous case with a double fork in chess. Suppose that Mary has never seen a double fork in chess but read all about it. What is Mary ignorant of before seeing a double fork in chess? It seems that in this case, we are inclined to think that Mary is ignorant of how a double fork in chess is manifest in experience rather than anything about what a double fork in chess is. If so, then once Mary enjoys a phenomenally conscious visual experience of a double fork in chess, the new knowledge she 
acquires is about the experience of a double fork in chess and not about what a double fork in chess is. Mary's knowledge of how a double fork is manifest in experience allows her to perceptually recognise a double fork and to discriminate it from, say, other tactical moves in chess. But the ability to perceptually recognise a double fork in chess does not entail that in acquiring this ability, Mary has acquired new knowledge of what a double fork itself is. In other words, the perceptual ability to recognise a double fork in chess is not the sort of sensitivity that we are after when we seek to argue that phenomenal conscious experience grants us epistemic access to the features of the object of experience rather than merely of the experience itself.

Appeal to the "as-structure" of experience captures the claim that in enjoying a phenomenally conscious experience of a double fork in chess, Mary acquires the perceptual ability to recognise double forks in chess. A conceptually refined sensory experience allows Mary to see an arrangement of objects instantiating the relevant sensible profile as a double fork in chess. Mary now knows how to recognise double forks in chess when she is presented with them. Since all that the capacity of perceptual recognition entails is that we learn how the relevant property is manifest in experience, then Johnston's appeal to the "as-structure" of experience is not able to capture the claim that the phenomenal character of Mary's experience of a double fork in chess plays an essential role in her learning what a double fork in chess is. Crucially for our purposes, this problem is carried over to the case of affect and value. If, as argued above, Johnston relies on the notion of the "as-structure" of experience in order to capture the claim that the phenomenal character of affective experience plays an essential role in presenting us objects $a s$ instantiating evaluative properties, then all that this claim captures is the thought that in enjoying an affective experience we learn something new about the way that the evaluative property is presented in experience rather than something new about the evaluative property itself.

The problem with Johnston's appeal to the "as-structure" of experience parallels the problem that some naïve realists argue afflicts intentionalism (see Sect. 2). Recall the objection put forward against intentionalism: insofar as the phenomenal character is conceived as constitutively determined by the representational properties of the experience, it is not clear why we should think that phenomenal character plays an essential role in the acquisition of new knowledge of the property of the object of experience rather than merely how the property is represented by the experience. Yet it is unclear how Johnston's appeal to the "as-structure" of experience is supposed to be an improvement on this since, as I argued above, appeal to the "as-structure" of experience allows us to capture solely the claim that phenomenal character plays an essential role in acquiring knowledge of how the property is manifested in experience, but not in the acquisition of new knowledge of what the property is. In both cases the worry concerns the obscurity of why the presence of the relevant phenomenal character is essential to the epistemic access to the relevant properties of the object of experience and this obscurity is due to the terms within which the phenomenal character is cashed out in the respective theories, namely the representational structure of experience in the case of the representationalist and the "as-structure" of experience in the case of Johnston. In 
virtue of this commonality, it is not clear how the "as-structure" of experience is meant to be an improvement on its representational counterpart in supporting the notion of affect as a disclosure of value.

\section{Phenomenal intentionalism and resemblance}

In the previous section I argued that Johnston's naïve realist commitments lead him to a position regarding affect and value that is vulnerable to the same charge that some Naïve Realists make against intentionalist's accounts of perceptual experience. Recent attempts to answer the naïve realist objection have relied on arguments from the "Phenomenal Intentionalism Research Project". 8 Phenomenal intentionalists distinguish themselves from more traditional versions of intentionalism by arguing that the intentionality of experience, or at least some versions of it, is constituted by phenomenal consciousness rather than the other way around. The challenge that phenomenal intentionalists face is to show how it follows from the claim that the intentionality of experience is constituted by phenomenal consciousness that phenomenal consciousness plays a necessary role in granting access to the features of the object of experience rather than merely of the experience itself. Montague's account of the inextricability of phenomenology and intentionality in emotional experience is an instance of applying a phenomenal intentionalist model of experience in attempting to argue for the claim that affect is a disclosure of value. In what follows, I argue that Montague's account, due to its commitments to a phenomenal intentionalist model of experience, is unable to secure the inextricability between phenomenology and intentionality in emotional experience. Therefore, I argue, phenomenal intentionalism is unable to provide a satisfying answer to the naïve realist objection. Ultimately, then, also the assumptions about experience embedded within phenomenal intentionalism are an obstacle to an account of affect as a disclosure of value.

There are three claims about emotional experience that play a key role in Montague's argument for the inextricability between affective phenomenology and evaluative intentionality. The first two claims are specific to emotional experience while the third one is a general claim about conscious experience applied to the emotional case. First, Montague puts the thought that emotional experience has an evaluative kind of intentionality in terms of emotional experience representing an evaluative property: 'Emotions, according to the present view, are essentially evaluative representations' (Montague 2014, 33). For instance, in feeling sad at the death of a friend, I represent my friend's death as sad. Second, Montague points out that affect has valence. The valence of affect refers to the characteristic of affect as either positive or negative. While the feeling of sadness is generally thought of as negative, the feeling of joy is generally thought of as positive. This point will become important in Montague's argument.

\footnotetext{
${ }^{8}$ See, e.g., Quassim Cassam's contribution in Campbell and Cassam (2014).
} 
Third, according to Montague, during a conscious, intentional experience the subject having the experience is aware both of an object distinct from the experience and of the experience itself. This is the awareness-of-awareness, or self-awareness, component of a conscious experience. The awareness-of-awareness relation is understood as an intentional relation: it is an awareness of. According to Montague, in being aware of having an experience, the subject is aware of the phenomenological character of the conscious experience. Importantly, Montague claims that during an experience, the subject is aware of the phenomenological properties of the experience as properties of the experience: 'phenomenological properties themselves present, phenomenologically, as what they are -properties of experience' (Montague 2014, 38). In being aware of the properties of the experience, the subject having the experience is aware of the sort of experience she is having precisely because she is aware of its properties. Since Montague conceives conscious experience as representing an object distinct from itself, the subject having the experience is intentionally related towards two objects: the object distinct from the experience and experience itself. Following Montague, I will refer to the object distinct from the experience as the primary object of experience (Montague 2009, 184). Since conscious experience represents the primary object of experience as having a property (or properties), the subject having the experience is aware of two sets of properties: the properties of the primary object (as experienced) and the properties of the experience itself. Montague applies this general framework of the intentionality of conscious experience to emotional experience. For instance in feeling sad, the subject having the experience is aware of the phenomenological properties of his experience of sadness and in being so aware he is aware that what he is experiencing is sadness. The phenomenological properties of an emotional experience are its affective and valenced qualities. During an experience of sadness, the subject having the experience is aware of the affective character of the experience and of its negative valence. Insofar as the subject experiencing sadness is also evaluating the primary object of experience as sad, he is aware of two sets of properties: the negatively valenced affective properties of the experience of sadness and the evaluative property of, say, his friend's death, namely its sadness.

How does the above support Montague's claim to the effect that affect and evaluation in emotional experience are inextricably linked? Montague wants to argue that the subject's awareness of the phenomenological properties of the emotional experience plays an essential role in the representation of the primary object having the evaluative property it is experienced as having. Montague adopts the following argumentative strategy (Montague 2009, 184-188; Montague 2014, 43-48):

a. Part of accounting for the way the primary object is represented in experience is to account for the property attribution we make in relation to that object.

b. The subject's awareness of the phenomenological properties of the experience contributes essentially to the property attributions we make.

c. Therefore, the awareness of the phenomenological properties of the experience contributes essentially to the representation of the primary object of experience. 
To illustrate. The awareness the subject has of the affective character of the experience is an essential component of the subject attributing the evaluative property 'sad' to a friend's death. Since accounting for the property attribution the subject makes is part of accounting for the representation of the primary object of experience, then the awareness of the phenomenological properties of the experience of sadness is accounting for the representation of the friend's death as sad. Unless the subject is aware of the phenomenological, affective properties of the experience of sadness, she would not attribute the evaluative property 'sad' to the friend's death.

The crux of the argument hinges on the putatively inextricable relation between self-awareness and representation that Montague argues for via the notion of property attribution. Montague tries to explain the link between self-awareness and representation by explaining how the awareness of the properties of experience leads to the representation of the properties that the primary object of experience is experienced as having. Montague argues that the subject, in being aware of both the properties of experience and the properties of the primary object of experience, finds a resemblance between the two. In the specific case of emotional experience, the properties of the experience the subject is aware of are its affective and valenced properties. The experience of sadness has the phenomenological properties of negative affect while the experience of joy has the phenomenological properties of positive affect. Montague then claims that we normally associate positive affect and negative affect with the positive value and negative value, or disvalue, of objects, respectively. Montague claims that 'The positive or negative evaluative phenomenology (the positive or negative affect) of an emotion represents the positive or negative quality of the object or state of affairs represented...negative and positive evaluative phenomenology represents disvalue and value' (Montague 2014, 46-47). Montague, then, argues that the reason why we attribute a value or disvalue to the primary object is due to the resemblance that the property of the primary object has to the property of the experience, that is, positive or negative affect. Representation is understood in terms of resemblance. Montague then proceeds to give the following account of evaluative property attribution in emotional experience:

The basic idea is that in experiencing the negative affect (the negative evaluative phenomenology) that is part of experiencing sadness, the negative affect is itself experienced as something of disvalue. This disvalue experienced in the experience of negative affect resembles the disvalue that is attributed to the state of affairs of the friend's death. It is then partly in virtue of this resemblance relation that the negative affect experienced as a property of experience represents the disvalue attributed to the friend's death. More strongly put, [] we feel the experience of feeling the disvalue of negative affect gets it exactly right about, completely conveys the character of, the purported objective property of disvalue. (Ibid. 47-48)

Notice that Montague has added an element to her account. Now, the resemblance is not anymore strictly between the valenced affective character of the experience and the (dis)value attributed to the primary object. Rather, it is between the (dis)value 
associated with the valenced affective character and the (dis)value attributed to the primary object. Montague's account is the claim that ultimately the subject attributes a disvalue to his friend's death because of a resemblance it has with the disvalue of the negative affect of the experience of sadness the subject is having.

\section{Phenomenal intentionality and qualia}

In what follows I aim to show that, in fact, Montague's account fails. I do so in three steps. First, I argue that from a phenomenological point of view the role assigned to affect by Montague's account of evaluative property attribution in emotional experience is implausible and I trace this implausibility to Montague's commitment to her underlying theory of experience. Second, I argue that Montague's notion of resemblance does not allow her to argue for the inextricable link between phenomenology and intentionality in emotional experience that she seeks to defend. Third, I argue that Montague's inability to secure the inextricability between phenomenology and intentionality lands her in a position vulnerable to the same charge made to qualia theories of phenomenology.

Montague's account of evaluative property attribution in emotional experience states that we attribute an evaluative property to the primary object of emotional experience because of a resemblance between the disvalue or value associated with the negative or positive affect of the experience and the disvalue or value that the primary object is experienced as having. In the experience of sadness at the death of a friend, the subject attributes the property "sad" to the friend's death due to a resemblance between the disvalue associated with the negative affective feel of the experience and the disvalue the friend's death is experienced as having. If so, then Montague's account entails that the attribution of the property of sadness to the friend's death involves both the evaluation of the affective character of our own experience, in the case of sadness as a disvalue, and the evaluation of the primary object of experience, say, as sad. Yet, from a phenomenological point of view, when I attribute sadness to the event of my friend's death due to the way I feel, it is the feeling that is experienced as what is performing the evaluation of the event. By contrast, Montague distinguishes between the evaluation of the primary object of experience i.e. my friend's death, and the role played by affect. The role played by affect in Montague's account of evaluative property attribution is merely of being evaluated and compared to the evaluation of the primary object of experience. In other words, in Montague's account, affect is left "inert" since the role it plays is merely one of being evaluated and compared to a second evaluation. Ultimately, then, Montague's account robs affect of precisely the sort of role that one would expect it to play in an account that seeks to show that in the absence of affect we are unable to experience the value or disvalue of the primary object of experience.

Crucially, the bestowal of this role to affect is traceable to Montague's underlying commitment to her theory of experience. Montague's attempt to show that intentionality necessitates phenomenality is via the argument that property attribution necessitates the awareness of the phenomenological properties of the experience. When applied to emotional experience, this translates as the claim that 
evaluative property attribution in emotional experience necessitates the awareness of the disvalue or value associated with the valenced affective character of the experience. In turn, the postulation of this sort of awareness is what leads Montague to conceive affect as being an object being evaluated rather than the object performing the evaluation. It is therefore her commitment to the phenomenal intentionalist distinctive credo that leads Montague to bestow such "inert" role to affect.

It is precisely Montague's commitment to the above theory of experience, and in particular to postulating two distinct acts of awareness, or evaluation in the case of emotional experience, that leads her in turn to attempt to bridge the two objects of awareness by postulating a relation of resemblance. Yet Montague's attempt to cash out the notion of representation in terms of resemblance is also deeply problematic. If we follow Montague and agree that accounting for property attribution is part of accounting for representation, and that representation is to be understood in terms of resemblance, then we end up with the following picture: I represent my friend's death as sad because of a resemblance between the sadness of my friend's death (evaluative property of the primary object) and the disvalue of the negative affective character of the feeling of sadness (evaluative property associated with the phenomenological property of emotional experience). But what kind of resemblance is there between the disvalue of an experience of sadness and the disvalue of a friend's death? What aspects of the disvalue of the negative affective character of sadness resemble the relevant aspects of the disvalue attributed to the friend's death? There does not seem to be an obvious answer. Indeed, if the (dis)value of the valenced affective character of an emotional experience does not resemble in any obvious way the (dis)value the subject normally attributes to the primary object, then why did Montague postulate the subject's awareness not only of the valenced affective character but also of the (dis)value associated with it? Why not postulate solely the awareness of the valenced affective character? The answer here seems to me to be that, again, there is no obvious way in which the valenced affective character of an emotional experience resembles the evaluative property normally attributed to the primary object. And since Montague postulates resemblance as doing the representational work, then by losing resemblance, Montague would lose representation. Insofar as this argument is in support of the inextricability thesis, if the phenomenology of an emotional experience does not play an essential role in the representation of an evaluative property, then the inextricable link between phenomenology and intentionality is severed. Montague's problem is that the phenomenological properties of an emotional experience do not seem to resemble the sort of evaluative properties that we normally attribute to the primary objects of emotional experiences.

Since Montague is unable to provide a plausible account of resemblance, her account is unable to secure the sort of inextricability between phenomenology and intentionality sought after. According to Montague's account of experience, what determines the phenomenal character of an experience are intrinsic phenomenological properties of the experience. Insofar as Montague is unable to secure the inextricability of phenomenology and intentionality, the phenomenal properties of these respective experiences are non-intentional, intrinsic features of experience, in 
many ways resembling qualia. They then partake in the intentionality of the respective experiences through resembling the properties that the primary object of experience is experienced as having. The negatively valenced affective property of the experience of sadness partakes in the experience's world-directed intentionality through its resemblance with the evaluative property of "sadness" that the primary object is experienced as having. But why should we think that, under the aegis of Montague's theory of experience, experiencing a phenomenal, intrinsic property of experience should disclose a property of the object of experience? What the experience of a new sort of affect would give us is the disclosure of a new property of experience, namely the intrinsic property of experience constituting its phenomenal character, and at most the knowledge that the relevant object of experience causes the experience to have that phenomenal character. But it does not disclose the evaluative property of the object. For all that has been said, then, the only thing that cannot be disclosed to Data is the intrinsic, phenomenological property of the emotional experience. That is, Data will never be able to feel an emotion. But nothing has been said to show that Data is therefore unable to "access" the same evaluative information as a human being. Since, then, Montague is unable to secure the inextricability between intentionality and phenomenology in emotional experience, her account is unable to show that affect is the disclosure of value.

\section{Conclusion}

In this paper, I argued that both Johnston's and Montague's accounts fail to deliver the promise of showing that affective experience, when appropriate, discloses not merely features of the experience but also of the object of experience, namely its value. Crucially, I traced the source of their problems to the underlying theories of perceptual experience they employ to theorise affect. In the case of Johnston, I argued that his commitment to a naïve realist model of experience leads him to a position that is vulnerable to the same objection as the one put forward by naïve realists against intentionalist models of perceptual experience. In the case of Montague, I argued that her account is unable to secure the inextricability between phenomenology and intentionality and therefore is unable to deliver the promise of phenomenal intentionalism not to relapse in positions vulnerable to the same charge put forward against qualia theories of experience. I submit, then, that insofar as contemporary accounts relying on the three dominant models of experience namely, naïve realism, different versions of intentionalism, and qualia theory- are problematic when theorising the notion of affect as a disclosure of value, and insofar as these problems are traceable specifically to the assumptions these models make regarding experience, then the core assumptions embedded within the three dominant models of experience, as found presently, are inadequate to show that phenomenally conscious affective experience, when appropriate, discloses not merely features of experience but also of the objects of experience, namely their value. 
In the Introduction, I mentioned the implausibility of attempting to capture the notion of affect as a disclosure of value by relying solely on theories of experience. If we want to show that affective experience is necessary to fully access evaluative properties, then we need to provide an account of evaluative properties that shows why this is the case. I now want to conclude this paper by suggesting what sort of account might have the resources to do so. The sort of material needed can be plausibly provided by accounts that seek to defend the objectivity of value, thus giving substance to the notion of disclosure, while respecting the inextricable relation between affect and value, thus conceiving disclosure as essentially affective. In particular, I have in mind the accounts of the objectivity of value by David Wiggins (1987) and John McDowell (1985). To be sure, I am not suggesting that we can take on board these accounts as they stand since neither argues that the affective component of emotional experience discloses value. Rather, I am suggesting that this sort of accounts of evaluative properties can potentially provide us with the sort of material needed to argue for affect as a disclosure of value. More specifically, these accounts propose an explanatory circularity between evaluative properties and affective responses. According to such circularity, we cannot adequately specify what an evaluative property is without referring to affective responses. In turn, we cannot adequately specify the constitution of affective responses without referring to the sort of properties they are responses to, namely value. In so doing, I am confident that we can identify features of affective experience that are necessary to render intelligible the notion of affect as a disclosure of value which have not been treated in an adequate manner, or at all, by accounts relying solely on theories of experience e.g. the formation of motivational states. Filling in the details of such a story is a task for another paper. ${ }^{9}$

Open Access This article is distributed under the terms of the Creative Commons Attribution 4.0 International License (http://creativecommons.org/licenses/by/4.0/), which permits unrestricted use, distribution, and reproduction in any medium, provided you give appropriate credit to the original author(s) and the source, provide a link to the Creative Commons license, and indicate if changes were made.

\section{References}

Brady, M. (2013). Emotional insight. Oxford: Oxford University Press.

Campbell, J., \& Cassam, Q. (2014). Berkeley's puzzle. Oxford: Oxford University Press.

Cowan, R. (2016). Epistemic perceptualism and neo-sentimentalism. Canadian Journal of Philosophy, $46(1), 58-81$.

Crane, T. (2000). The origins of qualia. In Tim Crane \& Sarah Patterson (Eds.), The history of the mindbody problem. London: Routledge.

Crane, T. (2009). Intentionalism. In A. Beckermann, B. P. McLaughlin, \& S. Walter (Eds.), The oxford handbook of philosophy of mind. Oxford: Oxford University Press.

Deonna, J., \& Teroni, F. (2012). The emotions: An introduction. London: Routledge.

Deonna, J., \& Teroni, F. (2014). In what sense are emotions evaluations? In R. Sabine \& T. Cain (Eds.), Emotion and value. Oxford: Oxford University Press.

Deonna, J. \& Teroni, F. (2015). Emotions as attitudes. Dialectica, 69, 293-311.

\footnotetext{
9 I would like to thank Naomi Eilan, an anonymous referee for Philosophical Studies, and in particular Matthew Soteriou for invaluable comments and suggestions on earlier drafts of this paper.
} 
Doering, S. (2007). Seeing what to do: Affective perception and rational motivation. Dialectica, 61, 363-394.

Farkas, K. (2013). Constructing a world for the senses. In U. Kriegel (Ed.), Phenomenal Intentionality. Oxford: Oxford University Press.

Goldie, P. (2000). The Emotions: A philosophical exploration. Oxford: Oxford University Press.

Goldie, P. (2002). Emotions, feelings and intentionality. Phenomenology and the Cognitive Sciences, 1, 235-254.

Goldie, P. (2007). Seeing what is the kind thing to do: perception and emotion in morality. Dialectica, 61, $347-361$.

Helm, B. (2001). Emotional reason: Deliberation, motivation, and the nature of value. Cambridge: Cambridge University Press.

Horgan, T., \& Tienson, J. (2002). The intentionality of phenomenology and the phenomenology of intentionality. In D. J. Chalmers (Ed.), Philoosphy of mind: Classical and contemporary readings. Oxford: Oxford University Press.

Johnston, M. (2001). The authority of affect. Philosophy and Phenomenological Research, LXIII, 181-214.

Johnston, M. (2004). The obscure object of hallucination. Philosophical Studies, 120(1/3), 113-183.

Kriegel, U. (2013). The phenomenal intentionality research program. In U. Kriegel (Ed.), Phenomenal Intentionality. Oxford: Oxford University Press.

Loar, B. (2003). Phenomenal Intentionality as the basis for mental content. In M. Hahn \& B. Ramberg (Eds.), Reflections and replies: Essays on the philosophy of Tyler Burge. Cambridge MA: MIT Press.

McDowell, J. (1985). Values and secondary qualities. In Ted Honderich (Ed.), Morality and objectivity. London: Routledge \& Kegan Paul.

Montague, M. (2009). The logic, intentionality, and phenomenology of emotion. Philosophical Studies, 145(2), 171-192.

Montague, M. (2014). Evaluative phenomenology. In S. Roeser \& Cain Todd (Eds.), Emotion and value. Oxford: Oxford University Press.

Montague, M. (2016). The given: Experience and its contents. Oxford: Oxford University Press.

Poellner, P. (2016). Phenomenology and the perceptual model of emotion. Proceedings of the Aristotelian Society, vol. CXVI, no.3.

Soteriou, M. (2016). Disjunctivism. London, NY: Routledge.

Tappolet, C. (2012). Emotions, perceptions, and emotional illusions. In C. Clotilde (Ed.), Perceptual Illusions: Philosophical and psychological essays. Basingstoke: Palgrave Macmillan.

Tye, M. (1992). Visual qualia and visual content. In T. Crane (Ed.), The contents of experience. Cambridge: Cambridge University Press.

Whiting, D. (2012). Are emotions perceptual experiences of value? Ratio (new series), 25, 93-107.

Wiggins, D. (1987). A sensible subjectivism? In D. Wiggins (Ed.), Needs, values, truth. New York: Oxford University Press.

Zagzebski, L. (2003). Emotion and moral judgement. Philosophy and Phenomenological Research, 66(1), 104-124. 